\title{
Efficient Identification and Referral of Low-Income Women at High Risk for Hereditary Breast Cancer: A Practice-Based Approach
}

\author{
G. Josepha, d \\ C. Kaplan ${ }^{\text {b J. Luce }}$ b \\ R. Lee ${ }^{c}$ \\ S. Stewart ${ }^{\mathrm{e}}$ \\ C. Guerrad \\ R. Pasick ${ }^{b, d}$
}

Departments of a Anthropology, History and Social Medicine, and ${ }^{b}$ Medicine, ${ }^{c}$ Cancer Risk Program, and ${ }^{\mathrm{d}}$ Helen Diller Family Comprehensive Cancer Center, University of California, San Francisco, San Francisco, Calif., and

eDepartment of Public Health Sciences, University of California, Davis, Davis, Calif., USA

\section{Key Words}

$B R C A \cdot$ Disparities $\cdot$ Hereditary breast and ovarian cancer •

Low income $\cdot$ Practice-based research

\begin{abstract}
Background: Identification of low-income women with the rare but serious risk of hereditary cancer and their referral to appropriate services presents an important public health challenge. We report the results of formative research to reach thousands of women for efficient identification of those at high risk and expedient access to free genetic services. External validity is maximized by emphasizing intervention fit with the two end-user organizations who must connect to make this possible. This study phase informed the design of a subsequent randomized controlled trial. Methods: We conducted a randomized controlled pilot study $(n=38)$ to compare two intervention models for feasibility and impact. The main outcome was receipt of genetic counseling during a two-month intervention period. Model 1 was based on the usual outcall protocol of an academic hospital genetic risk program, and Model 2 drew on the screening and referral procedures of a statewide toll-free phone line through which large numbers of high-risk wom-
\end{abstract}

(c) 2012 S. Karger AG, Basel

$1662-4246 / 12 / 0154-0172 \$ 38.00 / 0$

Fax +41613061234

E-Mail karger@karger.ch

www.karger.com
Accessible online at: www.karger.com/phg en can be identified. In Model 1, the risk program proactively calls patients to schedule genetic counseling; for Model 2 , women are notified of their eligibility for counseling and make the call themselves. We also developed and pretested a family history screener for administration by phone to identify women appropriate for genetic counseling. Results: There was no statistically significant difference in receipt of genetic counseling between women randomized to Model 1 (3/18) compared with Model 2 (3/20) during the intervention period. However, when unresponsive women in Model 2 were called after 2 months, 7 more obtained counseling; 4 women from Model 1 were also counseled after the intervention. Thus, the intervention model that closely aligned with the risk program's outcall to high-risk women was found to be feasible and brought more low-income women to free genetic counseling. Our screener was easy to administer by phone and appeared to identify high-risk callers effectively. The model and screener are now in use in the main trial to test the effectiveness of this screening and referral intervention. A validation analysis of the screener is also underway. Conclusion: Identification of intervention strategies and tools, and their systematic comparison for impact and efficiency in the context where they will ultimately be used are critical elements of practice-based research.

Copyright $\odot 2012$ S. Karger AG, Base

Galen Joseph, $\mathrm{PhD}$

University of California, San Francisco

1450 3rd Street, Room 551

San Francisco, CA 94158-9001 (USA)

Tel. +1 415514 9421, E-Mail gjoseph@cc.ucsf.edu 


\section{Introduction}

It has been common and accepted practice to develop disease-specific prevention and early detection interventions with each having its own dedicated infrastructure, staff and methods. Examples include many community- and clinic-based interventions to encourage breast, cervical or colorectal cancer screening [1-4]. The purpose of this study was to develop an efficient and sustainable practice-based model to integrate assessment and referral for hereditary breast and ovarian cancer syndrome (HBOC) into an existing communication channel used by large numbers of ethnically diverse low-income women. The primary focus is external validity, development of an intervention by and with end-users, minimizing additions or deviations from actual practice to maximize prospects for implementation [32].

This article reports the results of a pilot study comparing two approaches for engaging high risk low-income women in free genetic counseling to assess feasibility and fit for the two end-users of the intervention: a single-purpose statewide phone service which receives thousands of calls every year from low-income women for referrals to free cancer screening and an academic/ public hospital cancer risk program that delivers free genetic counseling and testing. We also developed and pretested a family history screener because existing tools were not suitable for efficient administration by phone.

\section{Background}

Clinical assessment followed by genetic testing of high-risk individuals is the recommended standard of care [5-7]. Women with deleterious BRCA mutations have as much as an $85 \%$ risk for breast cancer and $45 \%$ risk for ovarian cancer over the course of their lifetime compared with $12.2 \%$ for women in the general population [8-10]. Counseling, screening, treatment, and preventive measures associated with $B R C A$ testing have been shown to reduce morbidity and mortality and to improve quality of life [10-19]. A 2009 Cochrane review found that 'cancer genetic risk assessment is beneficial' for patients at risk of HBOC by reducing psychological distress and worry about breast cancer, improving accuracy of risk perception and increasing knowledge of breast cancer and genetics; 'however, more studies are required to assess the best means of delivering these services by different health professionals and in alternative locations, through a variety of interventions'[19]. Thus, there is a clear need for efficient large-scale risk assessment in or-

Identification of Low-Income Women at High Risk der to identify the small number of women who should be referred to genetic counseling.

Until recently, however, low-income women have not had the benefit of outreach or education on HBOC, nor have genetic counseling and testing for HBOC been widely available to them because there was no source of free or low-cost service. While the prevalence of $B R C A$ mutations is similar across US ethnic groups (with the exception of individuals with Ashkenazi Jewish ancestry), fewer than $13 \%$ of all women who receive BRCA testing are of non-European ancestry even though people of color, who are disproportionately low-income, make up $35 \%$ of the US population [20-24]. According to a review by Halbert et al. [25], the methods typically used to enroll women in risk assessment - including self-referral or referral by a physician, usually at the prompting of a patient - are less likely to occur among African American women and women of other groups who are known to have lower levels of knowledge and awareness of genetic counseling and testing [26].

\section{Referral for Genetic Counseling versus Referral for Genetic Testing}

Several assessment tools have been designed to predict likelihood of a BRCA mutation and thus appropriate ness for genetic testing (e.g. BRCAPRO, Myriad II, BOADICEA, PENN II) [27-31, 41]. However, there is no standard tool for determining referral to genetic counseling. Eligibility for genetic testing requires a complete pedigree, including enumeration of family members who have and have not had cancer, types of cancer and age at diagnosis. In contrast, identification of those who should be referred to obtain such a pedigree is based on a set of 'red flags' such as breast cancer before age 50, breast and ovarian cancer, bilateral breast cancer, and/or male breast cancer.

\section{Our Study}

The central premise of this study is that low-income women should have ready access to genetic risk assessment and that the strategies to make this possible must be sustainable and thus not require extraordinary measures or the creation of entirely new infrastructure. Ideally they should fit into existing structures and resources with minimal modification to personnel and procedures [32-34]. Our intervention has two end-users, the California Department of Health Services Every Woman Counts program (EWC), a toll-free telephone service that provides statewide referrals to free breast and cervical cancer screening with funding from the Centers for Disease 
Control and a state tobacco tax, and the University of California San Francisco (UCSF) Cancer Risk Program (CRP) with sites on campus and at San Francisco General Hospital (SFGH), the public hospital for the City and County of San Francisco. Through donor funds at UCSF and with support from the Avon Foundation at SFGH, free genetic counseling and testing is offered to low-income women from around the Bay Area. Our intervention is designed to identify low-income Bay Area EWC callers at high risk and refer them to UCSF or SFGH for free genetic services and to seamlessly fit this new service into the policies and procedures of each setting.

We recognized the EWC phone service as a potentially novel channel for reaching low-income women for varied preventive services based on a pilot study in which $49.5 \%$ of eligible callers were willing to participate in research on a topic unrelated to the purpose of their call [35]. Qualitative data from that study suggested that the unexpectedly high rate of participation was due to the trust engendered by EWC's provision of free screening, its multi-lingual capability and promotion of the service through credible local media. Based on this finding, we designed the current study to assess the potential of this communication channel to identify callers who are at high risk for breast/ovarian cancer and to refer them to genetic counseling/testing services. (To further explore this approach, we also tested the willingness of Asian American callers to discuss Hepatitis B testing [36]).

\section{Methods}

The study has 2 phases: Phase I, the focus of this report, consists of 2 components: (a) development and pretest of the Six-Point Scale family history screener and (b) an intervention pilot test comparing 2 models for integrating the risk identification and genetic counseling services: the EWC for access to large numbers of women and administration of a risk screener and the UCSF CRP for provision of free counseling and testing. Study components were reviewed and approved by the institutional review boards of the UCSF and Cancer Prevention Institute of California (where EWC is housed).

\section{Recruitment of Study Participants}

Study participants were recruited among callers to EWC. At the start of every call, Information Specialists collect demographic and contact information and enter it into a computer program. We adapted the program to identify eligible women using these criteria: county of residence (for proximity to the CRP), language of call (English or Spanish) and age (25 and over, the ages usually served by the CRP). At the conclusion of usual service, the Specialist invited study-eligible women to participate and conducted a short verbal consent.
Development of the Six-Point Scale Family History Referral Screening Tool

A key component of our intervention is a risk assessment tool that met the following criteria: (1) ease of use over the phone by EWC Information Specialists whose level of training (typically high school graduates) allowed only for asking simple straightforward questions and (2) brevity because the risk assessment and genetic counseling referral followed the EWC usual call service consisting of eligibility assessment and referral for cancer screening. When we began our study, only 2 tools were available to assess eligibility for genetic counseling, the Pedigree Assessment Tool (PAT), a web-based scoring system $[37,38]$ and the Family History Assessment Tool (FHAT), both designed for use by clinicians. Both tools are overly complex for our purposes because they include second- and third-degree relatives and calculate separate scores for maternal and paternal family history. The FHAT also takes into account multiple categories for age at diagnosis and the type/number of primary cancers (bilateral, multifocal, breast/ ovarian in a single individual).

To develop a more parsimonious screening tool, we adapted and simplified the PAT calling the new tool the 'Six-Point Scale' (fig. 1). Adaptation included identification of the minimum family history criteria for appropriate referral to cancer risk assessment and development of a weighting scheme that scored responses according to risk (i.e. higher risk responses, such as firstdegree relative diagnosed under age 50 or male breast cancer, were assigned higher scores). A threshold of 6 points indicated referral to genetic counseling. A genetic counselor conducted a preliminary test of the scale using the pedigrees of 7 genetic counseling patients to complete both the Six-Point and PAT scales and finding that the resulting scores appropriately qualified the patients for genetic counseling.

Like the PAT, the Six-Point Scale includes a series of questions, each with a weighted score. However, for the Six-Point Scale, respondents need only answer questions up to a total score of 6 , at which point the EWC computer program identifies callers as eligible for genetic counseling. The Six-Point Scale is further streamlined because it does not separately assess maternal and paternal lineages or include third-degree relatives, making it simpler for the staff administering it and the respondent. Since beginning our study, one validated genetic counseling referral tool has been published [40, 41]. The Referral Screening Tool (RST) also simplifies the screening process, consisting of a one-page table scored with a series of checks. However, all questions must be answered to arrive at a score. Table 1 summarizes and compares the features of the 4 scales.

\section{Pretest of the Six-Point Scale Family History Screener}

During development, we could not determine whether there was an advantage to beginning the questionnaire with a broad question that would reduce the number of respondents but which might be more difficult to answer, 'Have you or any of your blood relatives on your mother or father's side had breast or ovarian cancer?' We suspected such a question would increase the length of the call and the burden on Information Specialists. To ascertain the more efficient structure, we pretested 2 versions of the SixPoint Scale for ease of administration. The primary differences were the initial question and question order. Version 1 asks family history questions in a logical order beginning with the caller and then her closest to least close but still relevant relatives (moth- 
1. Have you ever been told by a doctor that you have breast cancer? 1a. No

1b. Don't Know

1c. If Yes, were you diagnosed before the age of 50 ?

$\begin{array}{rr} & \square=0 \\ & \square=0 \\ \text { Yes } & \square=4 \\ \text { No } & \square=2 \\ \text { Don't know } & \square=2\end{array}$

2. Have you ever been told by a doctor that you have ovarian cancer? 2a. Yes

2b. No

2c. Don't know

3. Do you have any Jewish ancestors?

3a. Yes

3b. No

3c. Don't know

4. Have any men in your family had breast cancer?

4a. Yes

$\square=6$

4b. No

$\square=0$

4c. Don't know

5. Have any of your blood relatives had ovarian cancer? 5a. Yes

5b. No

5c. Don't know

6. Has your mother had breast cancer?

6a. No

6b. Don't Know

$6 c$. If Yes, was she diagnosed before the age of 50 ?

$\square=0$

$\square=0$

$\square=0$
$\square=4$

No $\square=2$

Don't know $\quad \square=2$

7. Do you have any sisters who have had breast cancer? 7a. No

7b. Don't Know

$\square=0$

7c. If Yes, how many sisters were diagnosed with breast cancer?

$7 d$. If 1 or 2 , was she (either sister) diagnosed before the age of 50 ?

8. Do you have any daughters who have had breast cancer? 8a. No

8b. Don't Know

8c. If Yes, was she diagnosed before the age of $50 ?$

9. Have either of your grandmothers had breast cancer? 9a. No

9b. Don't Know

9c. If Yes, was she diagnosed before the age of $50 ?$

10. Have any of your aunts had breast cancer? 10a. No

10b. Don't Know

10c. If Yes, was she diagnosed before the age of 50 ?

Fig. 1. Six-Point Scale.

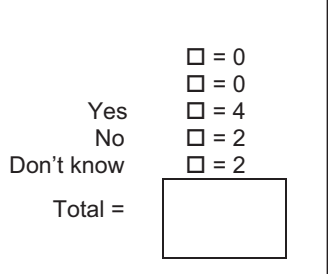

er, sisters, grandmothers, aunts) and asks about more common cancers first (breast before ovarian cancer). Version 2, in addition to beginning with the broad question mentioned above, asks the highest scoring questions first (e.g. ovarian cancer before breast cancer question).

Identification of Low-Income Women at High Risk
To complete 20 pretests, eligible callers were consented, randomized to one version (10 callers each with 5 English and 5 Spanish-speaking respondents) and asked the corresponding questions. Brief cognitive interviews with EWC callers were conducted by study staff within $24 \mathrm{~h}$ of the EWC call, and debrief interviews

Public Health Genomics 2012;15:172-180 
Table 1. Comparison of referral screening tools

\begin{tabular}{|c|c|c|c|c|}
\hline & PAT $[38,39]$ & RST [41] & FHAT [40] & Six-Point Scale \\
\hline Ashkenazi Jewish & 4 points/lineage & $\checkmark$ & - & 4 points \\
\hline Breast cancer at age $50+$ & 3 points/relative & $\begin{array}{l}\checkmark \\
\geq 2 \text { relatives in same lineage }\end{array}$ & $\begin{array}{l}4 \text { points/mother } \\
3 \text { points/sister } \\
2 \text { points/second- or third-degree } \\
\text { relative }\end{array}$ & $\begin{array}{l}2 \text { points/proband } \\
2 \text { points/relative }\end{array}$ \\
\hline Breast cancer before age 50 & 4 points/relative & $\checkmark$ & $\begin{array}{l}6 \text { points/age } 20-29 \\
4 \text { points/age } 30-39 \\
2 \text { points/age } 40-49\end{array}$ & $\begin{array}{l}4 \text { points/proband } \\
4 \text { points/relative }\end{array}$ \\
\hline Ovarian cancer & 5 points/relative & $\checkmark$ & $\begin{array}{l}7 \text { points/mother } \\
4 \text { points/sister } \\
3 \text { points/second- or third-degree } \\
\text { relative } \\
\text { Age of onset: } \\
6 \text { points/age }<40 \\
4 \text { points/age } 40-60 \\
2 \text { points/age }>60\end{array}$ & $\begin{array}{l}6 \text { points/proband } \\
4 \text { points/other relative }\end{array}$ \\
\hline Male breast cancer & 8 points/relative & $\checkmark$ & 4 points & 6 points \\
\hline Bilateral breast cancer & $2 \times$ related cancer & - & 3 points & 4 points/proband \\
\hline Relatives included & $\begin{array}{l}\text { Parents, siblings, children, } \\
\text { grandparents, aunts/uncles, } \\
\text { cousins, nieces/nephews, } \\
\text { great grandparents, great } \\
\text { aunts/uncles, distant } \\
\text { cousins, other }\end{array}$ & $\begin{array}{l}\text { Mother, sister, daughter, } \\
\text { grandmothers, aunts, any } \\
\text { male relative }\end{array}$ & $\begin{array}{l}\text { Include all affected relatives } \\
\text { to as far as third degree }\end{array}$ & $\begin{array}{l}\text { Parents, siblings, children, } \\
\text { grandparents, aunts, } \\
\text { cousins, any male relative }\end{array}$ \\
\hline Scoring & $\begin{array}{l}\text { Obtain total for each } \\
\text { lineage (paternal and } \\
\text { maternal) }\end{array}$ & Positive or negative & $\begin{array}{l}\text { Obtain family score based on each } \\
\text { member of the women's extended } \\
\text { family who had been diagnosed with } \\
\text { breast, ovarian, colon, or prostate } \\
\text { cancer; considering relationship of } \\
\text { proband to affected individual, age } \\
\text { of diagnosed and type/number } \\
\text { of primary cancers (bilateral, } \\
\text { multifocal, breast/ovarian); assess } \\
\text { each lineage separately }\end{array}$ & Obtain an overall total \\
\hline Threshold & $\geq 8$ points in either lineage & $\geq 2$ checks & $\geq 10$ points & $\geq 6$ points \\
\hline
\end{tabular}

with the 2 participating Specialists were conducted immediately following each pretest call session. Participants received a USD 20 gift card in appreciation for their time. Women identified as low risk via the screener were sent a flier after completion of the pretest with information about where to call if they had questions about their hereditary cancer risk. Women identified as high risk via the screener were sent an informational brochure and called by the UCSF CRP with an offer of free genetic counseling. The version of the scale found easiest to use has been implemented in the subsequent intervention pilot test and is undergoing a validation analysis.

\section{The Intervention Pilot Test}

We identified 2 different approaches for encouraging high-risk women to obtain genetic counseling, each being more compatible with one of the 2 systems involved (the EWC phone service or the
UCSF/SFGH CRP). Also, one required more staff effort while the other asked more of participants. Model 1 fits the CRP usual practice where referrals containing family history or personal medical history information are received from other clinics. These patients are called by a genetic counseling assistant and offered a counseling appointment. Thus, in Model 1, callers to EWC were told, 'Your answers [to our family history questions] show that it may be useful for you to talk with a genetic counselor. If you are interested in doing that, I can give your contact information to a genetic counselor at the Cancer Risk Program. The counselor will call you within 1 week to invite you to a free genetic counseling session, so you can learn more about what the cancer in your family means for you. Do you want the counselor to call you?'

Model 2 fits with EWC usual practices. EWC assesses eligibility and provides referrals to free mammograms and pap tests, and women are responsible for obtaining those services on their own. 


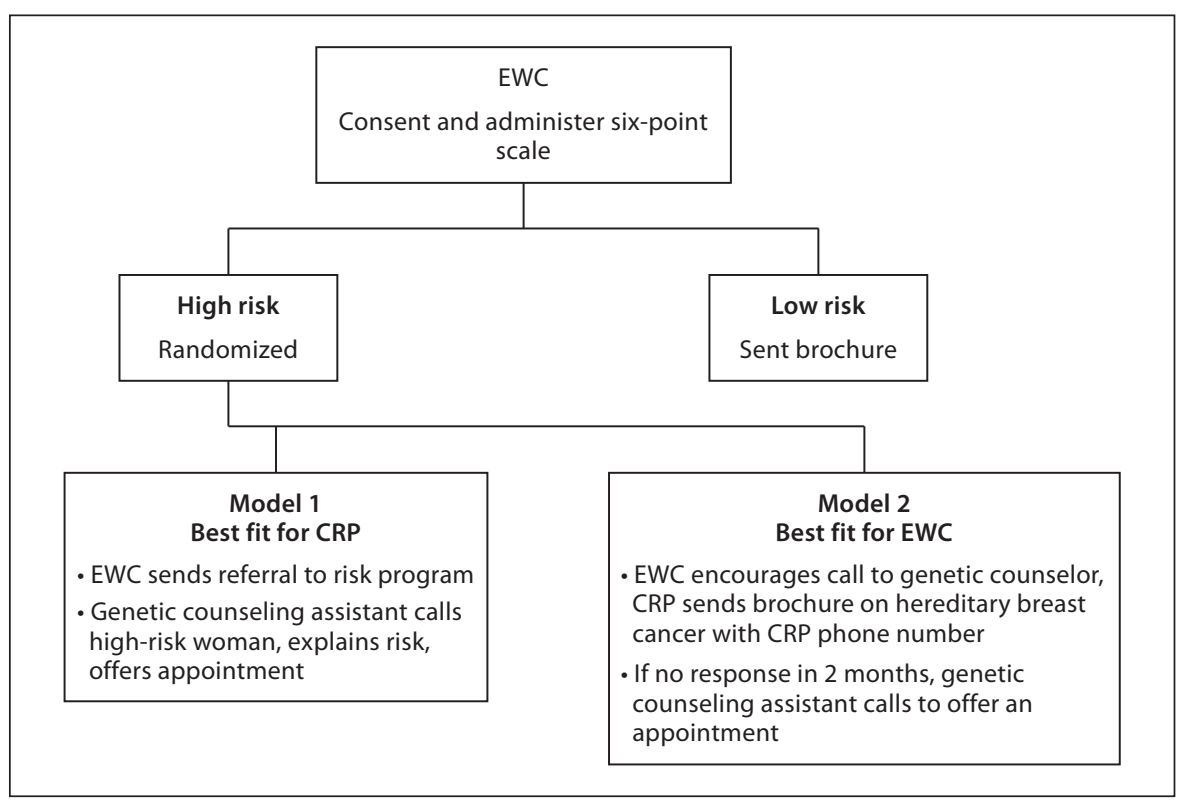

Fig. 2. Pilot test study design.

In Model 2, callers were told, 'Your answers show that it may be useful for you to talk with a genetic counselor. If you like, I will give you the contact information for the Cancer Risk Program where you can get free genetic counseling, so you can learn more about what the cancer in your family means for you. In addition, we will send you a brochure with more information and the contact information for the Cancer Risk Program. The counselor will be expecting your call. We strongly encourage you to call her.' EWC managers pointed out that phone service staff are not trained to discuss technical medical issues with callers and thus, initially preferred Model 2 because it deferred basic questions to the UCSF genetic counseling assistants who are trained to discuss basic concepts about family history and genetic counseling.

Because fit is a priority for this study, we conducted a pilot test to compare the ease of administration and impact of 2 strategies among 38 high-risk callers. An additional goal of the pilot test was to examine these interventions without the potential bias that can be introduced by administration of a baseline survey. (In the main intervention trial, baseline and post-intervention surveys are used to assess changes in anxiety, knowledge and cancer worry due to the intervention and due to attending genetic counseling.)

For the pilot test, the Six-Point Scale was administered to eligible consenting callers following usual EWC services. Those who were not candidates for genetic counseling (scoring 5 or lower on the screener) were told their answers indicated no need to speak with a genetic counselor, but that they would receive a brochure in the mail with additional information and a contact number for a genetic counselor at UCSF if they had questions. Women who scored 6 or higher ('high-risk callers') were randomly assigned by the computer to Model 1 or Model 2 (fig. 2). Two months following randomization, women in Model 2 who had not yet sought or obtained counseling were called by genetic counseling assistants. This two-month interval was considered the intervention period'.

Identification of Low-Income Women at High Risk

\section{Results}

\section{Pretest of Two Versions of the Six-Point Scale}

The debrief interviews with EWC Information Specialists indicated that both screeners were easy to use and that the callers did not have difficulty answering the questions. Callers also did not ask technical or medical questions that the Specialists were unprepared to answer. As we expected, for callers who responded 'no' to the first question on Screener \#2 'Have you or any of your blood relatives on your mother or father's side had breast or ovarian cancer?' the screening process was shorter since that was the only question they needed to answer. For respondents, who answered 'yes' to that first question, Specialists reported that the time to completion was comparable to that for Screener \#1. While Screener \#2 was thus faster to use than Screener \#1 for some callers, Specialists reported that it did not allow them sufficient time to develop rapport with the caller. One Specialist said that Screener \#1 'allows time for the caller to see that they [EWC] really care about them.' The Specialists also indicated that Screener \#2 did not allow sufficient time for callers to think through the cancer history of various family members.

The debrief interviews with callers showed that the genetic screener questions were easy to understand and to answer, although some participants indicated that they were not sure of their family history and that this uncertainty was a concern. Most participants reported that an-

Public Health Genomics 2012;15:172-180 
swering questions about family history of cancer over the phone in the context of the EWC call was comfortable.

\section{Intervention Pilot Test}

The 38 participants in the intervention pilot test ranged in age from 25 to 64 , with an average age of 47.8 . Participants were ethnically diverse: 15 (39\%) Hispanic, 13 (34\%) White, 5 (13\%) African American, 4 (11\%) Asian/ Pacific Islander, and 1 (2\%) unknown. Among Hispanic participants, 5 were Spanish speakers and 10 spoke English. Most participants had either completed high school (39\%) or some college (29\%). Among the others, 3 (7\%) had completed grade school, 7 (18\%) were college graduates and $2(5 \%)$ had some postgraduate training.

Overall, 17 out of 38 women (45\%) obtained genetic counseling. This included 7 women from Model 1 and 10 from Model 2, a difference that is not statistically significant. There were also no significant differences in counseling by race/ethnicity or language: those counseled included 2 of 5 African Americans, 2 of 4 Asian/Pacific Islanders, 5 of 15 Hispanics, 7 of 13 Whites, and 1 of unknown race/ethnicity. English speakers numbered 33, of whom 15 were counseled; 2 of 5 Spanish speakers obtained counseling. During the intervention period, 3 out of 18 women in Model 1 obtained counseling compared to 3 out of 20 for Model 2, also a nonsignificant difference. Of note is the fact that the majority of Model 1 women were contacted within 3 days of randomization, but for 3 women it took between 20 days and 4 months to make the initial contact after randomization. Women never counseled included those who could not be reached after numerous attempts (9), those who declined counseling (5), and those who initiated but never completed the appointment scheduling process (7).

Reports from both end-user organizations noted that the process went smoothly for each.

\section{Discussion}

The primary components of our intervention are: (a) the EWC phone service that attracts diverse low-income women; (b) a screening tool that can be administered over the phone by minimally trained staff; and (c) free genetic counseling and testing in a system designed to reach out to low-income women, routinely calling and offering genetic counseling. The purpose of the formative research was to link EWC and the CRP and simultaneously to minimize organizational burden and cost, and to maximize identification of high-risk women and their subsequent use of genetic counseling. We also developed and pretested a family history screener that efficiently identifies high-risk women by telephone.

Our findings indicate considerable receptivity among low-income and ethnically diverse women when offered the opportunity to discuss their family history and, if found to be eligible for genetic counseling, a similarly high degree of willingness to take advantage of the services. Our results underscore the necessity of calling high-risk low-income women to offer genetic counseling. This is particularly evident from Model 2 where only 3 high-risk women sought counseling on their own. Yet, 7 more women randomized to that arm subsequently obtained counseling once they were called. This contrasts with more affluent/insured women who are known to self-refer to genetic counseling. Thus, Model 1 was deemed the preferred strategy and is currently being tested for effectiveness in a larger randomized controlled trial.

\section{Conclusion}

Identification of intervention strategies and tools, and their systematic comparison for impact and efficiency in the context where they will ultimately be used is informative and desirable for practice-based research. In the words of Lawrence W. Green, 'If you want more evidencebased practice, you need more practice-based evidence'. [33].

Reaching out to low-income women to identify those at high risk for hereditary breast cancer can feasibly be integrated into a communication channel already widely used by this population and can readily connect them to academic and public hospital-based genetic services. This is critical since these are potentially very high-risk women who would otherwise not access these life-saving services. Toll-free phone lines that provide information and referral for free breast and cervical screening may be ideally suited for this purpose.

\section{Acknowledgements}

Support for this research comes from the National Cancer Institute, 1R01CA129096 PI: Dr. Rena Pasick. We also wish to acknowledge the Avon Foundation and the National Breast Cancer Foundation for resources to provide life-saving services to lowincome women. 


\section{References}

1 Mock J, McPhee SJ, Nguyen T, Wong C, Doan H, Lai KQ, Nguyen KH, Nguyen TT, Bui-Tong N: Effective lay health worker outreach and media-based education for promoting cervical cancer screening among Vietnamese American women. Am J Public Health 2007;97:1693-1700.

2 Robinson CM, Beach ML, Greene MA, Cassells A, Tobin JN, Dietrich AJ: Staffing time required to increase cancer-screening rates through telephone support. J Ambul Care Menage 2010;33:143-154.

- 3 Vernon SW, McQueen A, Tiro JA, del Junco DJ: Interventions to promote repeat breast cancer screening with mammography: a systematic review and meta-analysis. J Natl Cancer Inst 2010;102:1023-1039.

-4 Baron RC, Rimer BK, Breslow RA, Coates RJ, Kerner J, Melillo S, Habarta N, Kalra GP, Chattopadhyay S, Wilson KM, Lee NC, Mullen PD, Coughlin SS, Briss PA; Task Force on Community Preventive Services: Client-directed interventions to increase community demand for breast, cervical, and colorectal cancer screening a systematic review. Am J Prev Med 2008;35(suppl 1):S34-55.

-5 American Society of Clinical Oncology: American Society of Clinical Oncology policy statement update: genetic testing for cancer susceptibility. J Clin Oncol 2003;21: 2397-2406.

6 National Comprehensive Cancer Network: Genetic/Familial High-Risk Assessment: Breast and Ovarian V.1. Fort Washington, 2008.

7 US Preventive Services Task Force: Genetic risk assessment and BRCA mutation testing for breast and ovarian cancer susceptibility: recommendation statement. Ann Intern Med 2005;143:355-361.

8 King MC, Marks JH, Mandell JB; New York Breast Cancer Study Group: Breast and ovarian cancer risks due to inherited mutations in BRCA1 and BRCA2. Science 2003;302: 6436-6440.

9 Altekruse SF, Kosary CL, Krapcho M, Neyman N, Aminou R, Waldron W, Ruhl J, Howlader N, Tatalovich Z, Cho H, Mariotto A, Eisner MP, Lewis DR, Cronin K, Chen HS, Feuer EJ, Stinchcomb DG, Edwards BK (eds): SEER Cancer Statistics Review, 19752007. Bethesda, National Cancer Institute, 2010.

10 Domchek SM, Friebel TM, Neuhausen SL, Wagner T, Evans G, Isaacs C, Garber JE, Daly MB, Eeles R, Matloff E, Tomlinson GE, Van't Veer L, Lynch HT, Olopade OI, Weber BL, Rebbeck TR: Mortality after bilateral salpingo-oophorectomy in BRCA1 and BRCA2 mutation carriers: a prospective cohort study. Lancet Oncol 2006;7:223-229.

$\checkmark 11$ Prat J, Ribé A, Gallardo A: Hereditary ovarian cancer. Hum Pathol 2005;36:861-870.
12 American Cancer Society: Leading Sites of New Cancer Cases and Deaths - 2008 estimates. Cancer Facts and Figures 2008.

13 Nelson HD, Huffman LH, Fu R, Harris EL; U.S. Preventive Services Task Force: Genetic risk assessment and $B R C A$ mutation testing for breast and ovarian cancer susceptibility: systematic evidence review for the US Preventive Services Task Force. Ann Intern Med 2005;143:362-379.

14 Antoniou A, Pharoah PD, Narod S, Risch HA, Eyfjord JE, Hopper JL, Loman N, Olsson $\mathrm{H}$, Johannsson O, Borg A, Pasini B, Radice P, Manoukian S, Eccles DM, Tang N, Olah E, Anton-Culver H, Warner E, Lubinski J, Gronwald J, Gorski B, Tulinius H, Thorlacius S, Eerola $\mathrm{H}$, Nevanlinna $\mathrm{H}$, Syrjäkoski K, Kallioniemi OP, Thompson D, Evans C, Peto J, Lalloo F, Evans DG, Easton DF: Average risks of breast and ovarian cancer associated with $B R C A 1$ or BRCA2 mutations detected in case Series unselected for family history: a combined analysis of 22 studies. Am J Hum Genet 2003;72:11171130.

15 Guillem JG, Wood WC, Moley JF, Berchuck A, Karlan BY, Mutch DG, Gagel RF, Weitzel J, Morrow M, Weber BL, Giardiello F, Rodriguez-Bigas MA, Church J, Gruber S, Offit K; ASCO; SSO: ASCO/SSO review of current role of risk-reducing surgery in common hereditary syndromes. J Clin Onc 2006;24:28.

16 Domchek SM, Friebel TM, Singer CF, Evans DG, Lynch HT, Isaacs C, Garber JE, Neuhausen SL, Matloff E, Eeles R, Pichert G, Van t'veer L, Tung N, Weitzel JN, Couch FJ, Rubinstein WS, Ganz PA, Daly MB, Olopade OI, Tomlinson G, Schildkraut J, Blum JL, Rebbeck TR: Association of risk-reducing surgery in BRCA1 or BRCA2 mutation carriers with cancer risk and mortality. JAMA 2010;304:967-975.

17 Rodriquez E, Domchek SM: The prevention of hereditary breast cancer. Semin Oncol 2007;34:401-405.

18 Morgan D, Sylvester H, Lucas FL, Miesfeldt $S$ : Cancer prevention and screening practices among women at risk for hereditary breast and ovarian cancer after genetic counseling in the community setting. Fam Cancer 2009; 8:277-287.

19 Sivell S, Iredale R, Gray J, Coles B: Cancer genetic risk assessment for individuals at risk of familial breast cancer. Cochrane Database Syst Rev 2007;2:CD003721.

20 Meiser B, Eisenbruch M, Barlow-Stewart K, Tucker K, Steel Z, Goldstein D: Cultural aspects of cancer genetics: setting a research agenda. J Med Genet 2001;38:425-429.
21 Hall MJ, Reid JE, Burbidge LA, Pruss D, Deffenbaugh AM, Frye C, Wenstrup RJ, Ward BE, Scholl TA, Noll WW: BRCA1 and BRCA2 mutations in women of different ethnicities undergoing testing for hereditary breastovarian cancer. Cancer 2009;115:22222233.

22 Whittemore AS, Gong G, Itnyre J: Prevalence and contribution of $B R C A 1$ mutations in breast cancer and ovarian cancer: results from three U.S. population-based case-control studies of ovarian cancer. Am J Hum Genet 1997;60:496-504.

23 John EM, Miron A, Gong G, Phipps AI, Felberg A, Li FP, West DW, Whittemore AS: Prevalence of pathogenic BRCA1 mutation carriers in 5 US racial/ethnic groups. JAMA 2007;298:2869-2876.

24 US Census Bureau, Income Poverty and Health Insurance Coverage in the US: 2008, Current Population Reports. Series P60-236 and historical tables - tables 2 and 6, 2009.

25 Halbert CH, Kessler LJ, Mitchell E: Genetic testing for inherited breast cancer risk in African Americans. Cancer Invest 2005;23: 285-295.

26 Schaefer GB, Dunston GM: Health-care disparities in medical genetics; in Satcher D, Paimes RJ (eds): Multicultural Medicine and Health Disparities. New York, McGraw-Hill, 2006, pp 471-484.

27 Antoniou AC, Pharoah PP, Smith P, Easton DF: The BOADICEA model of genetic susceptibility to breast and ovarian cancer. $\mathrm{Br} \mathrm{J}$ Cancer 2004;91:1580-1590.

28 Evans DG, Eccles DM, Rahman N, Young K, Bulman M, Amir E, Shenton A, Howell A, Lalloo F: A new scoring system for the chances of identifying a BRCA1/2 mutation outperforms existing models including BRCAPRO. J Med Genet 2004;41:474-480.

-29 Berry DA, Iversen ES Jr, Gudbjartsson DF, Hiller EH, Garber JE, Peshkin BN, Lerman C, Watson P, Lynch HT, Hilsenbeck SG, Rubinstein WS, Hughes KS, Parmigiani G: BRCAPRO validation, sensitivity of genetic testing of $B R C A 1 / B R C A 2$, and prevalence of other breast cancer susceptibility genes. J Clin Oncol 2002;20:2701-2712.

30 Frank TS, Deffenbaugh AM, Reid JE, Hulick M, Ward BE, Lingenfelter B, Gumpper KL, Scholl T, Tavtigian SV, Pruss DR, Critchfield GC: Clinical characteristics of individuals with germline mutations in BRCA1 and $B R C A 2$ : analysis of 10,000 individuals. J Clin Oncol 2002;20:1480-1490.

31 Lindor NM, Johnson KJ, Harvey H, Shane Pankratz V, Domchek SM, Hunt K, Wilson M, Cathie Smith M, Couch F: Predicting $B R C A 1$ and BRCA2 gene mutation carriers: comparison of PENN II model to previous study. Fam Cancer 2010;9:495-502. 
32 Green LW, Glasgow R: Evaluating the relevance, generalization, and applicability of research: issues in external validity and translation methodology. Eval Health Prof 2006;29:126-153.

33 Green LW: Making research relevant: if it is an evidence based practice, where's the practice-based evidence? Fam Pract 2008;25(suppl 1):i20-i24.

34 Glasgow RE: What types of evidence are most needed to advance behavioral medicine? Ann Behav Med 2008;35:19-25.

35 Joseph G, Kaplan CP, Pasick RJ: Recruiting healthy low-income women to research: an exploratory study. Ethn Health 2007;12:497-519.
36 Joseph G, Nguyen T, Nguyen K, Stewart S, Pasick R: Efficient Identification of Low-Income Asian American Women at Risk for Hepatitis B, in preparation.

-37 Hoskins KF, Zwaagstra A, Ranz M: Validation of a tool for identifying women at high risk for hereditary breast cancer in population-based screening. Cancer 2006;107: 1769-1776.

38 Teller P, Hoskins KF, Zwaagstra A, Stanislaw C, Iyengar R, Green VL, Gabram SG: Validation of the pedigree assessment tool (PAT) in families with $B R C A 1$ and $B R C A 2$ mutations. Ann Surg Oncol 2009;17:240-246.
39 Gilpin CA, Carson N, Hunter AG: A preliminary validation of a family history assessment form to select women at risk for breast or ovarian cancer for referral to a genetics center. Clin Genet 2000;58:299-308.

40 Bellcross CA, Lemke AA, Pape LS, Tess AL, Meisner LT: Evaluation of a breast/ovarian cancer genetics referral screening tool in a mammography population. Genet Med 2009;11:783-789.

41 Bellcross C: Further development and evaluation of a breast/ovarian cancer genetics referral screening tool. Genet Med 2010;12: 240. 


\section{Erratum}

In the article by Joseph G, Kaplan C, Luce J, Lee R, Stewart S, Guerra C and Pasick R, entitled 'Efficient identification and referral of low-income women at high risk for hereditary breast cancer: a practice-based approach' [Public Health Genomics 2012;15:172-180, DOI: $10.1159 / 000336419]$, an error occurred in table 1 and figure 1.

Please find below the correct table and figure.

Table 1. Comparison of referral screening tools

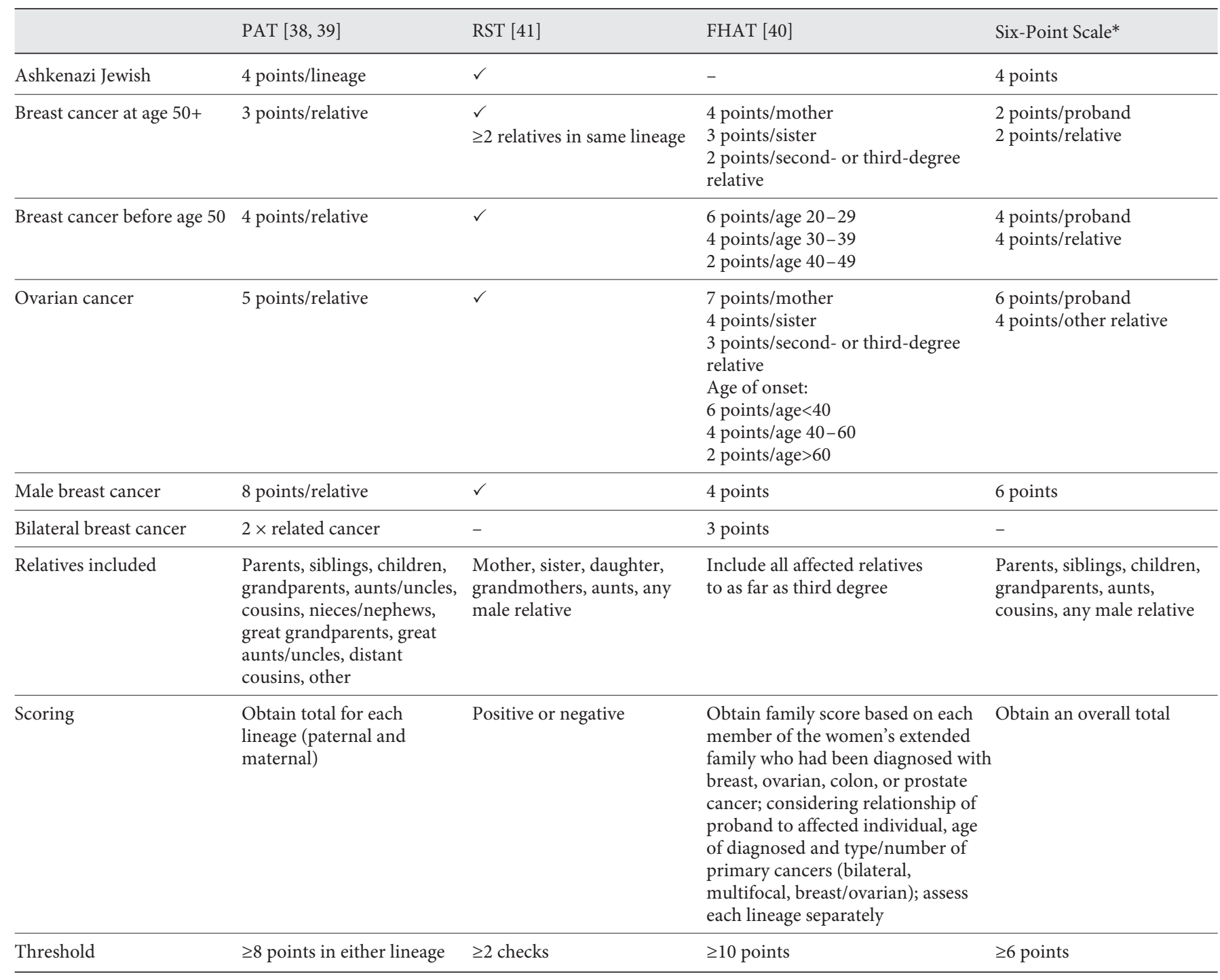

* The Six-Point Scale is structured to identify individuals who reach the threshold of six rather than to identify the exact number of points beyond six. Therefore, the number of points per relative diagnosed with breast cancer over and under age 50 is a generalization (see figure 1). 
SIX POINT SCALE

FINAL USED IN STATEWIDE STUDY (2/23/10)

(Once the score hits 6, stop and go on to the next step for scores 6 or above.)

1. Have you ever been told by a doctor that you have breast cancer? 1a. No

1b. Don't know

$\square=0$

1b. Don't know

$\square=0$

No $\square=2$

Don't know $\square=2$

If caller says she doesn't know age, prompt her by asking "do you think that it was before or after age 50 ?

2. Have you ever been told by a doctor that you have ovarian cancer?
2a. Yes
$\square=6$
2b. No
$\square=0$
2c. Don't Know
$\square=0$

3. Do you have any Jewish ancestors?

3a. Yes

3b. No

3c. Don't know

$\square=4$

$\square=0$

$\square=0$

4. Have any men in your family had breast cancer?

2a. Yes

$\square=6$

b. No

$\square=0$

2c. Don't Know

$\square=0$

5. Have any of your blood relatives had ovarian cancer?

5a. Yes

5b. No

5c. Don't know

$\square=4$

$\square=0$

$\square=0$

Blood Relatives include: Parents, Grandparents, Children, Aunts \& Uncles (not by marriage on both mother's and father's sides), cousins.

6. Has your mother had breast cancer?

6a. No

6b. Don't know

6c. If Yes, was she diagnosed before the age of 50 ? Yes $\square=4$

No $\square=2$

Don't know $\square=2$

If caller says she doesn't know age, prompt her by asking "do you think that it was before or after age 50 ? 7. Do you have any sisters who have had breast cancer?

$$
\text { 7a. No }
$$

7b. Don't know

7c. [If Yes]: How many sisters were diagnosed with breast cancer?

$$
\begin{aligned}
3 \text { or more } & \square=6 \\
2 & \square=4 \\
1 & \square=2
\end{aligned}
$$

7d. [If 1 or 2 sisters]: Was she (either sister) diagnosed before the age of 50 ?

$$
\text { Yes } \square=2
$$

No $\square=0$

Don't know $\quad \square=0$

If caller says she doesn't know age, prompt her by asking "do you think that it was before or after age 50 ?

8. Do you have any daughters who have had breast cancer?
8a. No
$\square=0$
8b. Don't know
$\square=0$
8c. If Yes, was she diagnosed before the age of 50 ?
Yes $\square=4$
No $\square=2$
Don't know $\square=2$

If caller says she doesn't know age, prompt her by asking "do you think that it was before or after age 50 ?

9. Have either of your grandmothers had breast cancer?
9a. No
$\square=0$
9b. Don't know
$\square=0$
9c. If Yes, was she diagnosed before the age of 50 ?
Yes $\square=4$
No $\square=2$
Don't know $\square=2$

If caller says she doesn't know age, prompt her by asking "do you think that it was before or after age 50 ? If total score is zero after question \#9, end call with script for scores of five or lower.

10. Have any of your aunts had breast cancer?
10a. No
$\square=0$
10b. Don't know
$\square=0$
10c. If Yes, was she diagnosed before the age of 50 ?
Yes $\square=4$
No $\square=2$
Don't know $\square=2$

If caller says she doesn't know age, prompt her by asking "do you think that it was before or after age 50 ?

Final Total $($ pages $1+2)=$

Fig. 1. Six-Point Scale. 